\title{
CONSIDERAÇÕES SOBRE A ESCOLHA DO DIREITO \\ MATERIAL APLICÁVEL AO MÉRITO DO LITÍGIO NA ARBITRAGEM INTERNACIONAL E O PAPEL DO ÁRBITRO
}

\author{
Matheus Martins Costa Mombach ${ }^{82}$ \\ Recebido em: 23/08/2018 \\ Aprovado em: 09/11/2018
}

\begin{abstract}
RESUMO
A arbitragem como método alternativo na resolução de conflitos decorrentes de relações contratuais tem assumido importância crescente na comunidade internacional. Neste trabalho, enfrentaremos o problema da autonomia da vontade na arbitragem internacional, perquirindo ser ou não possível que as partes escolham livremente o direito material aplicável ao mérito de seus litígios para, em um segundo momento, investigarmos como o árbitro deverá agir ante a ausência de escolha expressa. A metodologia empregada consistirá majoritariamente no recolhimento e exame dos posicionamentos doutrinários, nacionais e internacionais, acerca do tema em questão, assim como na pontual apuração de decisões dos Tribunais Arbitrais e de diplomas internacionais. Ao que tudo indica, concluiremos ser possível, ao menos nas hipóteses de arbitragens internacionais, que as partes escolham o direito material a ser aplicado ao mérito de seus litígios. Na hipótese de ausência de escolha expressa, deverá o árbitro extrair dos critérios objetivos do contrato - do texto ou do contexto contratual - solução que aponte para escolha implícita, porquanto inexiste, em nenhum estatuto arbitral moderno, requerimentos a respeito da forma que a escolha deverá assumir, nada impedindo que se infira da conduta das partes a existência de acordo implícito. Sendo impossível averiguar tal escolha, quer por ausência de indícios objetivos suficientes, quer por discordância entre os contratantes a respeito do direito a ser aplicado, poderá o árbitro recorrer a diplomas internacionais que, por sua vez, não oferecem um método específico a ser seguido, concedendo uma razoável discricionariedade ao adjudicador externo.
\end{abstract}

Palavras-chave: Arbitragem. Contratos internacionais. Autonomia da vontade. Escolha expressa. Escolha tácita.

\section{INTRODUÇÃO}

\footnotetext{
${ }^{82}$ Mestrando em Direito pela Universidade Federal do Rio Grande do Sul - UFRGS. Advogado.
} 
A arbitragem como método alternativo na resolução de conflitos decorrentes de relações contratuais, sobretudo de caráter comercial, tem assumido importância crescente na comunidade internacional, tratando-se do meio mais utilizado na resolução de litígios fora da esfera do Judiciário (DOLINGER; TIBURCIO, 2003, p. 19) porquanto permite o Direito amoldar-se às necessidades das partes oferecendo uma via eficiente para que estrangeiros pacifiquem seus conflitos sem submeterem-se a uma ordem jurídica nacional específica.

Sua eficiência justifica-se na medida em que, havendo partes situadas em países distintos, a opção pela submissão dos conflitos a um tribunal nacional apresentaria o risco de a parte estrangeira ver-se obrigada a litigar em outro país ante julgadores que provavelmente farão uso de critérios nacionais próprios, ao passo que tal parte deverá também buscar serviços advocatícios especializados nessa jurisdição estrangeira, recorrendo a advogados que não são de sua confiança. Além do mais, o processo será conduzido em língua provavelmente diversa da adotada no contrato celebrado, com as consequentes complicações de que seus documentos básicos deverão passar por traduções, gerando custos e atrasos, bem como favorecendo a formação de entendimentos equivocados (RODRÍGUEZ, 2010, p. 58).

Por outro lado, a opção pela arbitragem promoveria um método razoável para a solução destas disputas, sujeitando-as à sedes e árbitros neutros e competentes acerca de questões técnicas do comércio exterior e geralmente hábeis no manejo de idiomas distintos.

Embora o Brasil reconheça o recurso à arbitragem desde a época do Império ${ }^{83}$, assumindo até mesmo caráter obrigatório para determinadas matérias indicadas no Código Comercial de 1850 (ARAÚJO, 2012, p. 510), tal instituto passou a preencher especial espaço no ordenamento jurídico brasileiro após a entrada em vigor do Novo Código de Processo Civil (Lei 13.105/15), que objetivou modernizá-lo ao lhe conferir maior credibilidade. Dentre as inovações favoráveis à utilização da arbitragem, a lei equiparou a cláusula compromissória ao compromisso arbitral, pertencentes, agora, ao gênero "convenção de arbitragem".

No âmbito deste fenômeno em ascensão ${ }^{84}$, o artigo tem por objetivo provocar reflexões sobre determinadas questões que permanecem nebulosas, perquirindo de que

\footnotetext{
${ }^{83}$ Inicialmente prevista na Constituição Imperial de 1824 nos seguintes termos: “Art. 160 - Nas civeis e nas penaes civilmente intentadas poderão as partes nomear juizes arbitros. Suas sentenças serão executadas sem recurso se assim o convencionarem as mesmas partes". Em DOLINGER, Jacob; TIBURCIO, Carmen. Direito Internacional Privado (Parte Especial): Arbitragem Comercial Internacional. Rio de Janeiro: Renovar, 2003, p. 20.

${ }^{84}$ Constatado pela evolução dos números de novos casos registrados pela maioria das instituições arbitrais do mundo: "ICC: from 593 in 2006 to 794 in 2010; LCIA: from 137 in 2007 to 224 in 2011; SCC: from 141 in 2006 to 197 in 2010; DIAC: from 77 in 2007 to 186 in 2010; SIAC: from 90 in 2006 t 198 in 2010; HKIAC: from 394 in 2006 to 624 in 2010; ICDR (AAA): from 580 in 2005 to 888 in 2010". Em GAILLARD, Emmanuel. The emerging system of international arbitration: defining 'system'. ASIL Annual Meeting Proceedings, 2012, p. 3.
} 
maneira os sujeitos contratantes podem exercer a autonomia na escolha do direito material a ser aplicado na resolução do mérito de seus litígios e, na ausência de escolha expressa, como os árbitros devem agir para determiná-lo.

Para tanto, em um primeiro momento serão tecidas considerações pontuais acerca da possibilidade ou não de escolha do direito pelas partes no plano internacional e nacional para, no capítulo seguinte, investigarmos como o árbitro deverá atuar ante a inexistência de escolha expressa.

\section{DA ESCOLHA DO DIREITO MATERIAL APLICÁVEL AO MÉRITO DO LITÍGIO PELAS PARTES}

A despeito da consagração, nos mais diversos regulamentos e diplomas internacionais, da autonomia das partes para a escolha do direito material aplicável à resolução de seus litígios no âmbito da arbitragem internacional, é importante lembrar que esse entendimento nem sempre predominou pacificamente e, no direito brasileiro, parece suscitar controvérsias que se estendem até os dias de hoje. Neste sentido, os pontos que seguem pretenderão analisar como o reconhecimento dessa autonomia desenvolveu-se no plano internacional e no direito pátrio, respectivamente.

\subsection{No plano internacional}

Dolinger (1996, p. 247) adverte que "a regra básica, aceita universalmente, é a de que as partes podem escolher o direito a ser aplicado pelos árbitros à resolução das disputas”, entendimento igualmente manifestado por Gaillard, Fouchard e Goldman (1999, p. 785) ao notarem que praticamente todas as leis modernas de arbitragem reconhecem que, em situações internacionais, as partes são livres para determinar o direito aplicável ao mérito de suas disputas.

Trata-se, com efeito, da concretização da autonomia da vontade no plano jurídico internacional, constituindo-se um legítimo critério de conexão, na medida em que, conforme assinala Luiz Olavo Baptista (2011, p. 45), "ao invés de o sujeito submeter-se a uma lei, ele escolhe a que regerá o seu contrato. A sua vontade como que escapa ao império da lei a que normalmente se submeteria, para ir colocar-se sob o de outra, que escolheu". 
Neste sentido, nas palavras de Cretella Neto (2011, p. 195), pode-se afirmar que a autonomia da vontade no plano internacional relaciona-se com a "liberdade de as partes pactuarem, de comum acordo, as cláusulas contratuais da maneira que lhes forem mais convenientes, em especial a lei aplicável ao contrato internacional e o foro competente para julgar eventual litígio oriundo do contrato", limitando a atuação do árbitro.

Tal liberdade de escolha, todavia, nem sempre predominou pacificamente no plano da arbitragem internacional que, por um determinado período de tempo, a refutava em favor do clássico adágio locus regim actum, segundo o qual estaria o árbitro vinculado à lei do país sede da arbitragem, resultado de uma concepção, ou representação, monolocalizadora da arbitragem, no sentido empregado por Emmanuel Gaillard na clássica obra Legal Theory of International Arbitration $^{85}$.

A título de exemplo, foi de acordo com essa concepção restritiva que o Instituto de Direito Internacional, em resolução adotada em 1957, relativamente à questão do direito aplicável ao mérito do litígio, decidiu que:

o direito do local da sede do tribunal arbitral não se aplica necessariamente ao mérito do litígio, mas as regras de conexão em vigor nesse país deverão ser seguidas para determinar a lei que é competente a este respeito. As partes podem indicar aos árbitros, nos limites permitidos pelas regras de conexão do país da sede do tribunal arbitral, o direito sobre o qual deve ser baseada a sentença proferida quanto ao mérito (GAILLARD, 2014, p. 96, grifo nosso).

Segundo Poudret e Besson (2007, p. 571), na metade do século passado, o regime dominante era de fato a presunção de que, ao escolher a sede da arbitragem, as partes pretendiam submeter-se à sua lei material, em homenagem ao adágio quit eligit judicem eligit jus, entendimento aplicado notadamente na França, Alemanha e, principalmente, na Inglaterra, onde predominou por um maior período de tempo.

Contudo, apontam os autores que, em 1970, a House of Lords suavizou este critério sustentando, no caso Campagnie d'armement maritime, que uma cláusula arbitral escolhendo Londres como sede da arbitragem não necessariamente implicava no fato de que o contrato deveria submeter-se à lei inglesa, constituindo apenas uma indicação de direção neste sentido que, no caso, não foi suficiente para excluir a aplicação da lei francesa. Pouco tempo depois, a House of Lords entendeu, no caso James Miller v. Hitworth Street Estates, que a lei aplicável ao contrato poderá ser diferente daquela que governa a arbitragem, ainda que a primeira não tenha sido expressamente escolhida pelas partes.

\footnotetext{
${ }^{85}$ GAILlARD, Emmanuel. Teoria Jurídica da Arbitragem Internacional. Trad. Natália Mizrahi Lamas. Ed.
} Atlas: São Paulo, 2014 
Em breves linhas, estes casos representam um afastamento do sistema de submissão da lei da arbitragem e da lei aplicável ao mérito ao mesmo regime legal (POUDRET; BESSON, 2007, p. 572), fragilizando o antigo critério monolocalizador, incapaz de oferecer respostas eficientes às novas questões despertadas pela comunidade internacional que, por seu turno, já começava a enxergar o árbitro não mais como um membro de um foro em específico ou, nas palavras de Goldman, passando a ser o seu foro o mundo. ${ }^{86}$

Foi diante desse novo paradigma, descentralizador do fenômeno arbitral, que tanto o procedimento arbitral quanto a escolha do direito material aplicável ao mérito do litígio paulatinamente libertaram-se das correntes que os prendiam à ordem jurídica sede da arbitragem, especialmente a partir dos anos setenta do século passado, em função do reconhecimento da autonomia das partes para a eleição das normas que julgassem apropriadas à sua relação. ${ }^{87}$

Como marco relevante deste novo paradigma pode-se fazer menção ao entendimento adotado pelo próprio Instituto de Direito Internacional que, na sessão de Santiago de Compostela de 1989, repudiou a concepção monolocalizadora prevalecente trinta anos atrás em favor do reconhecimento da liberdade das partes e, subsidiariamente, dos árbitros, para a determinação do direito aplicável (GAILLARD; FOUCHARD; GOLDMAN, 1999, p. 786).

Não significa dizer, no entanto, que a sede tenha absolutamente perdido o seu papel, mas sim que ela passou a ser concebida como apenas uma dentre as demais ordens jurídicas que possam ter alguma conexão com o resultado da arbitragem, apresentada como mera possibilidade aberta aos árbitros, que deverão, por sua vez, observar primeiramente a escolha das partes.

Araújo (2012, p. 390) ensina que, no plano do direito internacional privado, é identificável, já no século XVI, o desenvolvimento do princípio da autonomia da vontade, esforço atribuído ao jurista francês Charles Dumoulin. A autora aponta para as lições de Otto Kahn-Freund, na ocasião de seu curso ministrado em Haia no ano de 1974, para quem o direito internacional privado acompanha os fatos da vida, razão pela qual, “por esta visão, até o século XVII, a única questão relevante dizia respeito à propriedade, o bem por excelência da época" (ARAÚJO, 2012, p. 390).

\footnotetext{
${ }^{86} \mathrm{Na}$ dicção de Gaillard (2014, p. 1), "é particularmente nesse curso que, rompendo com o pensamento ainda dominante à época, ele [Goldman] propõe a ideia fecunda segundo a qual 'os árbitros não têm foro' ou que, se fosse preciso lhes atribuir um, este seria o mundo. Isso significava, sob o prisma da filosofia da arbitragem, questionar a relação que a arbitragem internacional mantém com as ordens jurídicas nacionais".

87 Vale lembrar que é também reconhecida a possibilidade de as partes escolherem mais de um direito aplicável, cada um destinado a uma questão específica, prática que se convencionou chamar de dépeçage. Podem as partes, por exemplo, eleger uma lei para reger a responsabilidade contratual e outra para reger a responsabilidade extracontratual (POUDRET; BESSON, 2007, p. 578).
} 
Isso significa que, naquele século, "poderia surgir uma diferença entre o que determinava o regime de bens do casamento em relação à lei do lugar onde estava o imóvel” (ARAÚJO, 2012, p. 390), tornando necessária uma regra de direito internacional privado para regulá-la, tratando-se do limitado contexto no qual a visão de Dumoulin enquadrava-se.

Já no início século XX, a célebre decisão da Cour de Cassation francesa, em 1911, no caso American Trading Company c. Quebec Steampship, representou o marco fundamental no sentido do reconhecimento do princípio da autonomia da vontade, consagrando-o, mesmo sem mencioná-lo expressamente, e assim sepultando a tendência à aplicação da lex loci contractus (CRETELLA NETO, 2011, p. 195).

$\mathrm{O}$ entendimento estabelecido pela Corte francesa repercutiu em relevantes tratados internacionais do século XX, tais como a Convenção sobre a Lei Aplicável às Vendas de Caráter Internacional de Objetos Móveis Corpóreos (Haia, 15.05.1955, artigos 2 e 3), a Convenção sobre a Lei Aplicável às Obrigações Contratuais (Roma, 19.06.1980, artigo 3.1) e a Convenção sobre a Venda Internacional de Mercadorias (Haia, 22.12.1986, artigos 7 e 10).

Por outro lado, na esfera da arbitragem internacional, o papel fundamental exercido pela autonomia da vontade das partes na escolha do direito material aplicável pode ser constatado nos mais diversos diplomas e regulamentos internacionais, dentre os quais podemos citar, a título de exemplo, os princípios da UNIDROIT (art. 1.1), a Lei Modelo da UNCITRAL (art. 28) e as Regras sobre Arbitragem da CCI (art. 21).

Todavia, não obstante o prestígio conferido à liberdade das partes em grau bastante amplo no cenário internacional, tratando-se de critério universalmente aceito, o mesmo entendimento não se mostra pacífico no âmbito de certas ordens jurídicas nacionais. $\mathrm{Na}$ América Latina, por exemplo, Albornoz (2010, p. 1) constata que, em virtude de seu tradicional territorialismo, foi possível perceber uma demora no reconhecimento da autonomia da vontade, embora recentemente um interessante fenômeno tem sido identificado, claramente compelido pela pressão exercida pelo comércio internacional e pela necessidade de integração regional: até os países latinos mais reticentes passaram a integrar tratados de arbitragem internacional, nos quais a liberdade de escolha pelas partes é amplamente aceita.

Embora a ocorrência de tal adesão seja marcante, forçoso frisar que, na dicção da autora, "a mudança na mentalidade necessária para que legisladores e juízes reconheçam inteiramente a possibilidade de escolha da lei aplicável nos contratos internacionais pode, ainda, demorar alguns anos" (ALBORNOZ, 2010, p. 2) e que, especificamente no Brasil, essa percepção não encontra plena tranquilidade, tendo em vista as razões expostas a seguir. 


\subsection{No ordenamento jurídico brasileiro}

A faculdade de as partes contratantes determinarem a lei a ser aplicada foi objeto de longa divergência entre os autores clássicos da disciplina ${ }^{88}$. Parece, no entanto, que o assunto assumiu particular destaque após a mudança ocorrida entre a redação do artigo 13 e o artigo $9^{\circ}$ da Lei de Introdução às Normas do Direito Brasileiro, de 1942, dispondo que, "para qualificar e reger as obrigações, aplicar-se-á a lei do país em que se constituírem”, impondo o critério do local da celebração do ato (locus regit actum).

A partir dessa norma, parte da doutrina passou a sustentar a impossibilidade de se reconhecer a autonomia da vontade no ordenamento jurídico brasileiro, em uma clara afronta, segundo Gomes e Winter (2016, p. 352), ao princípio da liberdade fundamental de as partes, em uma relação contratual, elegerem a lei aplicada. Para os autores, "observe-se que neste aspecto, a opção do legislador foi pela adoção de um critério territorial: o local da celebração do ato".

Para Dolinger (2006, p. 98), influenciada pela doutrina clássica nas suas preocupações com normas imperativas, continuando impressionada com a mudança ocorrida entre os artigos supracitados, "a moderna doutrina brasileira vem desempenhando nos últimos 20 anos um papel equivocado no plano teórico e prático". Isto porque, para o autor, tal doutrina vem atuando em detrimento de tudo que tem se produzido no direito estrangeiro e no direito convencional, minando a imagem do Brasil no exterior, porquanto "desatentos às opiniões daqueles que mostraram como se pode e deve interpretar o artigo $9^{\circ}$ e seus parágrafos da LICC de maneira favorável à escolha da lei aplicável pelas partes” (DOLINGER, 2006, p. 98).

Todavia, de acordo com Araújo (2012, p. 396) “a LICC, no seu artigo 9ª não menciona o princípio da autonomia da vontade e, embora muitos juristas sejam a favor, o princípio é proibido", donde que "somente com a revisão da LICC, e a adoção dos princípios consagrados na Convenção sobre o Direito Aplicável aos Contratos Internacionais, realizada pela CIDIP V (México, 1994) poder-se-á permitir de forma segura a utilização do princípio da autonomia da vontade em contratos internacionais" (ARAÚJO, 2012, p. 397).

Tal posicionamento é, contudo, alvo de críticas por parte de Dolinger (2006, p. 99), para quem "um princípio é um princípio, e como tal está acima do direito positivo e de suas

\footnotetext{
${ }^{88}$ Para uma análise acurada, ver DOLINGER, Jacob. A autonomia da vontade para escolha da lei aplicável no direito internacional privado brasileiro. Em: LEMES, Selma Ferrira; CARMONA, Carlos Alberto; MARTINS, Pedro Batista (coords.). Aribtragem: estudos em homenagem ao prof. Guido Fernando da Silva Soares. In memoriam. São Paulo: Atlas, 2007.
} 
regras, e ninguém tem autoridade para proibir um princípio baseado no silêncio da lei, ou em qualquer outro fator".

Ainda, para Cravo (2015, p. 304), a situação brasileira estaria amenizada com a entrada em vigor, em 2014, da Convenção de Viena sobre Contrato de Compra e Venda Internacional, que consagra a autonomia da vontade no seu espectro de incidência. Aponta a autora que, da mesma forma, a Lei de Arbitragem brasileira (Lei n. ${ }^{\circ}$ 9.307/1996), “dá uma luz à questão, ao expressamente permitir, dentro de seus subprocedimentos, a autonomia da vontade" (CRAVO, 2015, p. 304).

É precisamente nesta linha que Nitschke (2015, p. 35) acentua não parecer ter acerto na hermenêutica que restringe a autonomia das partes, em especial após o advento da Lei de Arbitragem, lex posteriori, que, "se não leva ao afastamento dessa interpretação restritiva, no mínimo leva à mitigação de sua dureza", ao prever que as partes podem escolher, livremente, as regras de direito que serão aplicadas na arbitragem (art. $2^{\circ}, \S 1^{\circ}$, da Lei).

Diante dessa previsão, Nitschke (2015, p. 26) entende que a Lei de Arbitragem "arejou o claustro da Lei de Introdução e espanou seus dispositivos poeirentos, inserindo a autonomia privada como via prioritária dessa definição", razão pela qual o ordenamento jurídico brasileiro, na esteira da maioria dos ordenamentos jurídicos nacionais modernos, passou a consagrar a autonomia das partes nos contratos de arbitragem internacionais, alterando, de igual forma, o papel do art. $9^{\circ}$ da LINDB, de norma cogente à cânone interpretativo para os casos de omissão das partes ou, então, "para afastar as raras situações de escolha absurda dos contratantes" (NITSCHKE, 2015, p. 26).

Seguindo esse entendimento, Verçosa (2006, p. 449) leciona que "em face da redação de seu artigo $2^{\circ}, \S 1^{\circ}$, pode-se concluir que a Lei de Arbitragem adotou expressamente a autonomia da vontade das partes quanto à eleição da lei aplicável, desde que estas elejam a arbitragem para a solução das possíveis controvérsias entre elas advindas", havendo, ainda, maiores debates acerca da extensão dessa autonomia às arbitragens internas.

Relacionado a essa questão, Lee (2011, p. 7) explica que, ao unificar o tratamento legislativo da arbitragem interna e da arbitragem internacional em um mesmo diploma legal, “o legislador fomentou dúvidas quanto à aplicação do princípio de autonomia da vontade na determinação do direito aplicável ao mérito do litígio". Para o autor, o princípio da autonomia da vontade das partes, como princípio fundamental do direito internacional privado, "deve-se restringir às relações contratuais internacionais" (LEE, 2011, p. 7) e que, havendo conexão exclusivamente com um único país, deve-se aplicar imperativamente o direito interno deste Estado. 
Além disso, Gomes e Winter (2016, p. 364) defendem que o princípio da autonomia da vontade das partes deve ser entendido como um elemento basilar dentro das relações jurídicas privadas, porquanto através dele "os contratantes podem eleger - livremente - as normas e a legislação a ser aplicável para regulamentar uma relação contratual”, tratando-se de requisito essencial ao bom funcionamento do mercado globalizado e transfronteiriço, posto que, não raro, a solução ofertada internamente por uma ordem jurídica nacional pode não corresponder aos interesses das partes, sendo capaz de, inclusive, inviabilizar a celebração de determinado negócio. Sendo assim, nas palavras dos autores:

em um mundo globalizado, no qual as relações jurídicas privadas são cada vez mais complexas, nada mais natural do que permitir às partes a escolha da lei a ser aplicada para regulamentar referidas relações contratuais, vez que se trata de um direito fundamental dos próprios contratantes, em buscar a melhor solução para resolver o seu negócio jurídico (GOMES; WINTER, 2016, p. 365).

Esta é a razão pela qual os autores defendem que a Lei de Arbitragem veio corrigir a falha cometida pelo legislador de 1942, ao retirar a autonomia das partes na escolha do direito aplicável, resgatando tal princípio, basilar do direito civil, por tratar-se de um direito fundamental aplicado às relações jurídicas privadas (GOMES; WINTER, 2016, p. 365).

Ademais, é nesse sentido que Dolinger (2007, p. 107) aponta para o fato de que o debate em torno da admissão pelo legislador brasileiro da autonomia das partes para determinação do direito aplicável ao contrato internacional deveria ter cessado desde que a lei de arbitragem expressamente autorizou os contratantes a escolher a lei aplicável ao processo arbitral, inexistindo razão para as partes terem o direito de, na arbitragem, fixar a lei que será aplicada na solução de sua desavença, ao passo que, na hipótese de solução judicial, não gozarem da mesma prerrogativa.

Já Cretella Neto (2011, p. 262) elogia a legislação brasileira pelo fato de conferir ampla autonomia às partes na arbitragem, conquanto entenda que essa autonomia refere-se à lei aplicável à clausula arbitral e não ao contrato em sua totalidade, que ainda permanece sujeito às restrições da antiquada LICC. No seu ponto de vista, não seria possível afirmar de maneira conclusiva que a legislação brasileira confira ampla autonomia às partes em relação à lei aplicável ao contrato, de modo que, por ora, "plena autonomia, no Direito brasileiro, só existe em relação à lei aplicável à arbitragem" (CRETELLA NETO, 2011, p. 262).

Maristela Basso (1994, p. 201), por sua vez, afirma com prudência que, diante de um contrato internacional onde há cláusula de escolha de lei, a questão desta escolha derrogar a regra contida no art. $9^{\circ}$, caput, da LICC, é "extremamente difícil e objeto de debate por parte de nossos doutrinadores, e que não encontra uma resposta na jurisprudência". Para tanto, 
aconselha que o melhor para um negociador seria procurar, na medida do possível, compatibilizar o contrato com as leis aplicáveis potencialmente, concluindo que "nesta linha de raciocínio, entendemos que o art. $9^{\circ}$, caput, da LICC, como norma de ordem pública, não pode ser afastado pela vontade das partes" (BASSO, 1994, p. 201).

A partir do exposto, é possível notar a complexidade da questão suscitada que, longe de encontrar uma resposta final comum na doutrina, continua despertando inúmeros debates no cenário nacional.

Em apertada síntese, podemos concluir que, não obstante nos domínios do direito internacional privado brasileiro a autonomia da vontade não seja plenamente reconhecida pelos doutrinadores nacionais, é possível vislumbrar, ao menos no plano da arbitragem internacional, em virtude do permissivo legal disposto no art. $2^{\circ}, \S 1^{\circ}$ da Lei de Arbitragem, uma resposta um pouco mais segura, ainda que não unívoca, quanto à possibilidade de escolha do direito aplicável.

Daí que, para Souza Júnior (2002, p. 442), a Lei de Arbitragem representou uma verdadeira revolução no direito internacional privado brasileiro por conferir "eficácia à eleição feita pelas partes no contrato, não somente em relação às regras de um dado ordenamento estatal, mas também àquelas que constituem direito não estatal".

O mesmo diploma legal ainda permite as partes convencionarem que a arbitragem se realize com base nos princípios gerais de direito, nos usos e costumes e nas regras internacionais de comércio ( $\operatorname{art.} 2^{\circ}, \S 2^{\circ}$ ), o que denota, a princípio, a opção do legislador pelo respeito à autonomia da vontade.

\section{A CONDUTA DO ÁRBITRO DIANTE DA INEXISTÊNCIA DE ESCOLHA EXPRESSA DAS PARTES}

A despeito das divergências apontadas anteriormente e partindo do pressuposto de que as partes gozam de autonomia para determinar o direito a ser aplicado ao mérito de suas disputas, pode-se afirmar que, havendo escolha expressa que conduza o árbitro a sua identificação, nenhum problema parece surgir. Deverá o árbitro, nestes casos, priorizar a escolha dos contratantes, nos limites dos bons costumes e da ordem pública, de acordo com o art. $2^{\circ}, \S 1^{\circ}$ da Lei de Arbitragem brasileira.

Na prática, via de regra, a escolha expressa das partes é respeitada, conforme aponta Ole Lando (1986, p. 107), ao afirmar que "não se conhece nenhum caso no qual um árbitro 
desconsiderou a escolha das partes com base na falta de conexão com o sistema legal pretendido", bem como que diversas decisões asseguram a escolha das partes ainda que a lei eleita não tenha conexão com o contrato, hipótese na qual se entende que as partes tenham optado por uma lei neutra ou melhor desenvolvida para ser aplicada.

Suscitam dúvidas, todavia, as hipóteses nas quais o negócio apresenta-se lacunoso, no qual a escolha expressa não é possível de ser identificada de maneira clara. A atuação do árbitro diante destas situações desperta indagações na medida em que o contrato é um produto da regulação privada dos próprios interesses, razão pela qual, nas palavras de Martins-Costa e Nitschke (2012, p. 1249), “a possibilidade de uma intervenção externa - de juízes e ou de árbitros - para esclarecer ou modificar seu conteúdo, jamais foi aceita com tranquilidade”.

Destaca-se que, por vezes, a incompletude contratual ocorre por espontânea vontade das partes. É o caso, por exemplo, das grandes obras de construção, nas quais o contrato deve constituir um instrumento "apto a solucionar e regrar problemas técnicos, operacionais, econômicos, jurídicos, e até políticos, não passíveis de previsão e de regramento pontual na data de sua conclusão" (MARTINS-COSTA; NITSCHKE, 2012, p. 1249), tornando indesejável, ou até mesmo impossível, a elaboração de um instrumento contratual rígido e extenso, apto a prever todo tipo de situação que possa vir a surgir no desenvolver de sua execução.

A flexibilidade contratual é, portanto, um atributo necessário e desejável em determinados casos, havendo que se levar em conta as lições de Fernando Araújo (2007, p. 347), no sentido de que "negociações minuciosas envolvem custos de transação, dentre os quais despontam os custos de oportunidade do tempo dedicado à negociação”, bem como que as partes podem desejar deixar para momento posterior a forma de resolução de problemas que não passam de meras possibilidades no momento da negociação inicial, preservando intacta a sua flexibilidade na forma de encararem as contingências suscetíveis de interferirem com a relação contratual futura.

O autor aponta que é preciso reconhecer que "uma negociação muito empenhada na invocação de direitos pode fazer degenerar a confiança reciproca e o desejo de cooperação num regateio antagônico entre partes que implicitamente se afastam uma da outra em direção aos seus bastiões de legitimidade" (ARAÚJO, 2007, p. 347), o que evidencia, em certos casos, a preferência pela informalidade e pela remissão para as normas sociais.

A lacunosidade contratual relativa à escolha do direito material aplicável ao mérito do litígio também pode ser explicada por outros fatores. Por um lado, é possível cogitar que as partes conscientemente tenham optado por não estabelecer nenhum direito aplicável, visto que 
tal escolha poderia acarretar em desgastes desnecessários à relação, traduzindo-se muitas vezes em maiores custos de transação.

Por outro lado, também podemos imaginar hipótese na qual as partes, demasiadamente envolvidas e preocupadas com os demais aspectos da contratação, que não raro costumam ocupar bastante tempo e demandar a atuação de diversos profissionais, tenham silenciado acerca do direito aplicável inconscientemente, por um simples esquecimento ou desinteresse.

O silêncio das partes gera, portanto, inúmeros debates, sendo considerado, segundo Lee (2011, p. 7), um dos pontos da especificidade da arbitragem comercial internacional que a lei brasileira negligencia completamente.

Neste contexto, Gaillard, Fouchard e Goldman (1999, p. 788) apontam para uma distinção clara entre a existência de um consenso entre as partes a respeito do direito aplicável e a forma que este consenso deverá tomar. De acordo com os autores, nenhum estatuto arbitral moderno contém requerimentos acerca da forma que a escolha deverá assumir, nada impedindo, portanto, que os árbitros infiram da conduta das partes a existência de um acordo implícito a respeito do direito aplicável.

Poudret e Besson (2007, p. 577) corroboram esse entendimento acentuando que é de fato reconhecido que a escolha do direito aplicável não está submetida a nenhum requerimento formal e poderá ser realizada de maneira expressa, a partir de uma cláusula contratual ou adendo, ou tacitamente, quando resultar do comportamento das partes quando ambos invocarem o mesmo direito.

Portanto, ao passo que a escolha expressa não apresenta maiores dificuldades, "a escolha implícita exigirá do interprete ou juiz um estudo mais profundo das circunstâncias de cada caso, a fim de que a real vontade das partes possa ser interpretada" (CRAVO, 2015, p. 304).

Ainda, ensina Baptista (2011, p. 52) que, na Europa Ocidental, consolidou-se na doutrina que o princípio da autonomia teria aplicação ainda que as partes não tenham expressamente disposto no negócio jurídico, desde que essas tenham anuído implicitamente.

Neste sentido, parece correta a divisão apontada por Ole Lando (1986, p. 107), para quem os casos de escolha implícita da lei dividem-se em duas categorias: a primeira onde a intenção é demonstrada com uma razoável certeza através dos termos do contrato ou das circunstâncias do caso, havendo uma escolha tácita do direito, e a segunda onde os fatos do caso não suportam ou apontam para esta escolha tácita.

Portanto, a identificação da escolha tácita é atividade a ser conduzida com cautela, porquanto a correspondente vontade das partes deverá resultar de maneira inequívoca dos 
termos do contrato ou das circunstâncias do caso. De acordo com Gaillard, Fouchard e Goldman (1999, p. 788), a intenção das partes deve ser certa, constituindo um requisito essencial que os árbitros não podem relegar.

Para Leible (2011), devem haver indícios que apontem a existência de uma escolha tácita do direito, e somente quando, tendo em consideração todas as circunstâncias do caso concreto, todos ou a maior parte destes indícios apontarem para um ordenamento concreto, pode-se cogitar a existência desta escolha.

A esse entendimento alinha-se Biagioni (2010, p. 26) para quem a escolha tácita da lei deverá resultar de uma "certeza razoável" das circunstâncias do caso. Desta forma, "a dicotomia entre a escolha expressa e a escolha tácita torna-se uma consequência unicamente da forma diversa" na qual as partes manifestaram a vontade de tornar uma determinada lei aplicável à sua relação.

É que, nas lições de Yntema (1952, p. 352), é geralmente aceito, sob a égide do princípio da autonomia da vontade, que qualquer conduta das partes implicando na escolha de um direito específico terá o mesmo efeito que uma estipulação expressa. Todavia, Poudret e Besson (2007, p. 577) ressaltam que muitos autores e decisões inferiram da possibilidade de existência de uma escolha tácita do direito aplicável o fato de que a vontade das partes poderia igualmente resultar de uma ausência total de uma escolha, que em determinados casos poderia ser interpretada como uma escolha "negativa" das partes.

Tal escolha negativa resultaria tanto da incapacidade das partes de decidirem a respeito do direito aplicável quanto do desejo de se excluir da relação os seus respectivos direitos nacionais, pretendendo ver aplicadas somente regras de direito anacionais.

Para os autores, na ausência de circunstâncias específicas que permitam concluir ser este o caso, tais interferências seriam hipotéticas e arriscadas. Em outras palavras, entendem que é perigoso concluir, do silêncio das partes, a intenção destas em remover sua relação do âmbito de qualquer direito nacional.

Vejamos, a título de exemplo, a decisão do ICC Case n. 12.193 (Lebanese distributor v. German manufacturer), de junho de 2004, sediado em Bale, na Suíça, tratando-se de uma disputa resultante de um contrato exclusivo de distribuição entre uma empresa fabricante alemã e uma empresa de distribuição libanesa. Ante a inexistência de qualquer cláusula expressa no contrato determinando a lei aplicável ao mérito, as partes, discordando tanto da escolha quanto do método empregado para determiná-la, pediram para que o Tribunal Arbitral decidisse a esse respeito. 
Na decisão, o Tribunal entendeu que os testemunhos escritos e depositados durante os debates e as declarações das testemunhas não permitiram detectar com precisão as intenções genuínas das partes, bem como que a escrita ambígua e estranha da cláusula contratual não permitia demonstrar uma inequívoca e clara escolha das partes em favor da lei suíça.

Apontou o Tribunal que "de fato, se é geralmente admitido, no direito internacional privado comparado, que não é necessário um acordo explícito entre as partes quanto à lei aplicável, a sua demonstração de vontade deverá ser, contudo, certa”, o que não ocorreu no caso concreto.

Portanto, diante da inexistência de uma vontade clara, procedeu o Tribunal no emprego de métodos que dispõe para este fim, partindo da aplicação cumulativa das regras de conflito das leis Libanesa, Alemã e Suíça, concluindo que elas convergiam para a aplicação da lei libanesa.

Neste caso, o requerido havia igualmente solicitado a aplicação da lex mercatoria, em particular os princípios gerais de direito derivados da UNIDROIT, entendendo o Tribunal que, se a lex mercatoria tivesse de ser aplicada de fato, deveria atuar em complementariedade à lei libanesa, porquanto não haver interesse em aplicar aquela no lugar desta já que ambas possuiam previsões similares. Também decidiu o Tribunal que a aplicação da lex mercatoria não é motivada no caso em que exista ligações estreitas entre o contrato e uma determinada lei nacional.

Assim, Ole Lando (1986, p. 107) elenca como critério que possibilita identificar uma escolha tácita das partes o fato delas terem, por exemplo, feito uso de uma fórmula contratual corrente em determinado país, bem como escolhido a sede da arbitragem neste mesmo país que, por sua vez, também é o país de performace do contrato.

Ainda, de acordo com Neels e Fredericks (2011, p. 106), a existência de um acordo tácito ou implícito pode ser inferido e interpretado a partir de diversas maneiras. Ensinam os autores que determinados códigos referem-se somente a possibilidade de recurso às provisões contratuais, ao passo que outros referem-se tanto aos termos contratuais quando à conduta ou comportamento das partes, ou, ainda, aos termos contratuais e às circunstâncias do caso.

Nitschke (2015, p. 37), por seu turno, aponta determinadas circunstâncias objetivas nas quais os árbitros podem apoiar-se para depurar uma escolha implícita dos contratantes, como a nacionalidade das partes, a natureza do negócio, o objeto da transação, eventuais referências esparsas no contrato a legislação estatal ou transnacional, usos e costumes regularmente tidos para contratos similares e do mesmo ramo, eventual convergência das normas de conflito dos países a que pertencem os litigantes, dentre outros. 
É certo, portanto, que o árbitro não está vinculado a critérios como o da sede da arbitragem, na medida em que "o árbitro internacional não tem foro, o que lhe confere autonomia quanto à escolha do direito aplicável ao mérito" (LEE, 2011, p. 6).

Tal autonomia não parece significar, entretanto, uma liberdade irrestrita, na medida em que o seu primeiro dever sempre será o de "perquirir em que medida a solução para a lacunosidade encontra-se no próprio contrato, examinando elementos textuais e contextuais que eventualmente possam informar essa colmatação" (NITSCKE, 2015, p. 37).

Isso porque, conforme as lições de Martins-Costa e Nitschke (2012, p. 1284), toda lacunosidade é relacional, sendo "a partir do texto contratual e de seu contexto que o árbitro deve perquirir quando e em que medida a incompletude encontra-se no texto contratual".

Os autores lecionam que cada contrato é dotado de uma ratio contractus que denota sua coerência interna, razão pela qual há de ser tido "como um todo coerente do qual possa o intérprete, escavando a mencionada lógica interna com base nos elementos textuais e contextuais, extrair, razoavelmente, determinado sentido apto a aclarar as suas expressões ambíguas ou contraditórias" (MARTINS-COSTA; NITSCHKE, 2012, p. 1284).

A busca por critérios objetivos dentro do texto e ou do contexto contratual impede, por um lado, uma discricionariedade apta a ensejar um ativismo arbitral indesejável, ao passo que confere uma maior segurança jurídica e previsibilidade à decisão.

Aponta-se, ainda, a existência de diplomas internacionais que oferecem critérios para a escolha do direito pelo árbitro, ante a impossibilidade de revelá-la a partir de uma escolha tácita dos contratantes, como nas situações em que cada parte pretende ver aplicado um direito distinto, distanciando-se de um acordo capaz de revelar uma intenção em comum.

A Convenção Europeia de Arbitragem Comercial Internacional, por exemplo, dispõe que, inexistindo uma indicação pelas partes relativamente ao direito aplicável, os árbitros deverão aplicar o direito apropriado de acordo com as regras de conflito que julguem aplicáveis ${ }^{89}$, regra adotada também pela Lei Modelo da UNCITRAL de $1985^{90}$.

Já as regras da Câmara Internacional de Comércio (ICC Rules) dispõem que, na ausência de escolha expressa, o tribunal arbitral deverá aplicar as regras de direito que julgar

\footnotetext{
${ }^{89}$ Article VII - Applicable Law. 511. The parties shall be free to determine, by agreement, the law to be applied by the arbitrators to the substance of the dispute. Failing any indication by the parties as to the applicable law, the arbitrators shall apply the proper law under the rule of conflict that the arbitrators deem applicable. In both cases the arbitrators shall take account of the terms of the contract and trade usages.

${ }^{90}$ Artigo 28. Regras aplicáveis ao mérito da disputa. Na falta de tal designação pelas partes, o tribunal arbitral aplicará a lei designada pela norma de conflito de leis que considerar aplicável.
} 
$\operatorname{apropriadas}^{91}$, conferindo maior discriscionariedade ao árbitro na medida em que suprime a necessidade de passar pelas regras de conflito de leis.

Sendo assim, na ausência de indicação das partes, bem como sendo impossível extrair dos critérios objetivos do contrato alguma solução viável, os diplomas relevantes de arbitragem internacional nem sempre impõem um método específico a ser seguido, permitindo que os árbitros o determinem, conquanto não signifique liberdade total de escolha.

Por fim, Ole Lando (1986, p. 110) bem nota que, ao justificar sua decisão, o árbitro geralmente possuirá uma dupla preocupação. Por um lado, deverá persuadir as partes, em especial a parte sucumbente, de que a sua decisão é correta e justa. Por outro, deverá ter certeza que sua sentença será executável no país ou nos países nos quais a execução for solicitada.

Para o autor, isso implica no fato de que muitos árbitros tendem a justificar suas conclusões referindo-se não somente ao direito que eles julguem apropriado à disputa mas também a outros direitos com conexão com as partes ou com o objeto da matéria em disputa, razão pela qual o árbitro frequentemente irá referir-se ao direito da parte sucumbente para mostrar que este confirma a sua decisão.

\section{CONSIDERAÇÕES FINAIS}

Na lição de Bittar (2010, p. 138), a pós-modernidade caracteriza-se por um "estado reflexivo da sociedade ante suas próprias mazelas, capaz de gerar um revisionismo de seu modus actuandi, especialmente considerada a condição de superação do modelo moderno de organização da vida e da sociedde". Neste sentido, a revisão do modus actuandi do Direito Privado nos últimos dois séculos protagonizou substanciais transformações em seus institutos, sem oferecer, no entanto, qualquer resposta final ou definitiva.

Afirmou Wald (2007, p. 457) que, partindo dos diagnósticos e das visões dos sociológos e dos economistas, "conclui-se que há entre eles um denominador comum irrefutável: o desaparecimento de um mundo que possuía algumas certezas, permitindo que os riscos fossem avaliados". Neste contexto, o autor bem lembra que o início do século XX conhecia um universo ainda relativamente estável e um futuro considerado previsível, num

\footnotetext{
${ }^{91}$ Article 21: Applicable Rules of Law. 1) The parties shall be free to agree upon the rules of law to be applied by the arbitral tribunal to the merits of the dispute. In the absence of any such agreement, the arbitral tribunal shall apply the rules of law which it determines to be appropriate.
} 
momento, por exemplo, em que o homem comum ainda acreditava na ilusão da moeda estável.

Ao decorrer do século passado, determinados paradigmas do direito revelaram-se incapazes de acompanhar a evolução da sociedade e da econômia, caracterizando um cenário de constantes vacilações e incertezas no qual o próprio contrato encontrou-se em berlinda, conforme extrai-se do celebre e polêmico enunciado de Grant Gilmore (1995, p. 1) para quem "assim como Deus, o contrato está morto".

Assim como o contrato, as codificações igualmente foram postas à prova. É o que Martins-Costa (1998, p. 131) aduz ao apontar que "o Código Civil, na contemporaneidade, não tem mais por paradigma a estrutura que, geometricamente desenhada como um modelo fechado pelos sábios iluministas, encontrou a mais completa tradução na codificação oitocentista".

Por outro lado, a sua inspiração hodierna vem da Constituição, farta em modelos jurídicos abertos, a qual corresponde um Código não-totálitário, com “janelas abertas para a mobilidade da vida, pontes que o ligam a outros corpos normativos - mesmo os extrajurídicos- e avenidas, bem trilhadas, que o vinculam, dialeticamente, aos princípios e regras constitucionais" (MARTINS-COSTA, 1998, p. 131).

É nesta linha de raciocínio que Wald (2007, p. 457) indica que, enquanto o legislador do Código Napoleônico e do nosso Código Civil de 1916 partia da premissa que podia prever e regulamentar tudo, "definindo os detalhes da parede meeira e do beiral dos tetos", o juiz do século XXI deve aplicar princípios gerais, devido às lacunas da lei.

Lembra também que, além disso, "nas questões técnicas, sofisticadas e urgentes, o processo judicial está cada vez mais inadequado para fornecer soluções em tempo útil” (WALD, 2007, p. 457), o que explica o recurso das partes à arbitragem, a fim de garantir "não somente a interpretação e a aplicação das regras estabelecidas, como também a manutenção e gestão do contrato, que, muitas vezes, não pode ser interrompido em razão das perdas incomensuráveis que isso representaria" (WALD, 2007, p. 457).

Ao passo que o Novo Código Civil modernizou o instituto, dando-lhe maior credibilidade, determinadas questões continuam obscuras demandando atenção de quem pretende se dedicar ao assunto. Dentre elas, apontamos para as dificuldades despertadas em função do reconhecimento, ou não, da autonomia da vontade no direito internacional privado brasileiro, entendida esta como a liberdade de as partes designarem o direito a ser aplicável para a resolução de seus litígios. 
Com efeito, o artigo não teve a pretensão descabida de esgotar as possíveis conclusões do tema, mas sim pincelar certos aspectos relevantes para a sua compreensão e reflexão. Assim concluimos, em apertada síntese, que, embora grande parte da doutrina nacional não reconheça a plenitude da autonomia da vontade no ordenamento jurídico brasileiro, tal entendimento não parece se estender à hipótese das partes optarem livremente pela arbitragem, ocasião na qual se outorga a estas, via de regra, a possibilidade de escolherem o direito a ser aplicado ao mérito de seus litígios, sobretudo pela hermenêutica do art. $2^{\circ}, \S 2^{\circ}$, da Lei de Arbitragem.

Na situação de as partes não terem expressamente indicado o direito aplicável e diante do fato de que nenhum estatuto arbitral moderno contém requisitos especificos a respeito da forma que a escolha deverá assumir, caberá ao árbitro identificá-lo, inferindo do texto e ou contexto contratual a existência de uma escolha implícita.

Conquanto a escolha implícita demande critérios de razoável certeza, determinadas circunstâncias objetivas poderão apoiar a decisão do árbitro que, por sua vez, não está mais vinculado ao critério da sede da arbitragem.

$\mathrm{Na}$ hipótese de não ser possível inferir qualquer escolha implícita, quer por ausência de indícios objetivos suficientes, quer por discordância entre os contratantes acerca do direito a ser aplicado, apontamos para a existência de diplomas internacionais que oferecem critérios para a determinação do direito pelo árbitro, como a Convenção Europeia de Arbitragem Comercial Internacional, a Lei modelo da UNCITRAL e as regras da Câmara Internacional de Comércio.

Tais diplomas, em geral, não impõem um método específico a ser seguido, concedendo uma razoável discriscionariedade aos árbitros que, no processo decisório, atentarão também para a necessidade de sua sentença ser de fato executável no país ou nos países nos quais a execução for solicitada, razão pela qual é frequente a referência ao direito da parte sucumbente para mostrar que este confirma a sua decisão.

\section{REFERÊNCIAS}

ALBORNOZ, Maria Mercedes. Choice of Law in International Contracts in Latin American Legal Systems. Journal of Private International Law, vol. 6, n.1, 2010, p. 23-58.

ARAÚJO, Fernando. Teoria Econômica do Contrato. Ed. Almedina: Coimbra, Jan, 2007. 
ARAÚJO, Nadia de. Direito Internacional Privado: Teoria e Prática Brasileira. $5^{\mathrm{a}}$ ed. Rio de Janeiro: Renovar, 2012.

BAPTISTA, Luiz Olavo. Contratos Internacionais. São Paulo: Lex Editora, 2011, p. 45.

BASSO, Maristela. A autonomia da vontade nos contratos internacionais do comércio. Revista da Faculdade de Direito, v. 12, n. 12, 1994.

BIAGIONI, Giacomo. Tecniche internaziona lprivatistiche fondate sulla volontà delle parti nel Diritto dellUnione Europea. Cuadernos de Derecho Transnacional, v. 2, n. 2, p. 16-32, 2010 .

BITTAR, Eduardo CB. O direito na pós-modernidade. Sequência: Estudos Jurídicos e Políticos, v. 29, n. 57, p. 131-152, 2010.

CRAVO, Daniela Copetti. Escolha Implícita da Lei nos Contratos Internacionais: Caso Farady Reinsurance v. Howden North America. Cadernos do Programa de Pós Graduação em Direito da UFRGS, vol. 10, n.1, 2015, p. 298-321.

CRETELLA NETO, José. Contratos Internacionais: cláusulas típicas. Campinas: Millennium, 2011.

DOLINGER, Jacob. International Commercial Arbitration. Course on International Law XXIII, Organization of American States: 1996, p. 115-135.

DOLINGER, Jacob; TIBURCIO, Carmen. Direito Internacional Privado (Parte Especial): Arbitragem Comercial Internacional. Rio de Janeiro: Renovar, 2003

GAILLARD, Emmanuel. FOUCHARD, Philippe. GOLDMAN, Berthold. Fouchard, Gaillard, Goldman on International Commercial Arbitration. Kluwer Law International, 1999.

GAILLARD, Emmanuel. Teoria Jurídica da Arbitragem Internacional. Trad. Natália Mizrahi Lamas. Ed. Atlas: São Paulo, 2014.

“system”. ASIL, 2012. The Emerging System of International Arbitration: Defining 
GILMORE, Grant; COLLINS, Ronald KL. The death of contract. 1995.

GOMES, Eduardo Biacchi; WINTER, Luis Alexandre Carta. Contratos internacionais e arbitragem: o direito fundamental à liberdade das partes na escoha da lei a ser aplicável nas relações privadas. Revista Jurídica, v. 1, n. 42, 2016. p. 349-365

LANDO, Ole. The law applicable to the merits of the dispute. Arbitration International, v. 2, n. 2, p. 104-115, 1986.

LEE, João Bosco. A lei 9.307/96 e o direito aplicável ao mérito do litígio na arbitragem comercial internacional. Revista de Direito Bancário e do Mercado de Capitais, vol. 11, p. 247-359, 2011.

LEIBLE, Stefan. La importancia de la autonomía conflictual para el futuro del Derecho de los contratos internacionales. Cuadernos de Derecho Transnacional, v. 3, n. 1, p. 214-233, 2011.

LEMES, Selma Ferreira; CARMONA, Carlos Alberto; MARTNIS, Pedro Batista. (Coordenadores). Arbitragem: estudos em homenagem ao Prof. Guido Fernando da Silva Soares, In Memoriam. São Paulo: Atlas, 2007.

MARTINS-COSTA, Judith; NITSCHKE, Guilherme Carneiro Monteiro. Contratos duradouros lacunosos e poderes do árbitro: questões teóricas e práticas. Revista de arbitragem, v. 2, 2012.

MARTINS-COSTA, Judith. O direito privado como um sistema em construção. Revista da Faculdade de Direito da UFRGS, Porto Alegre, n. 15, p. 129-153, 1998.

NEELS, Jan L.; FREDERICKS, Eesa A. Tacit choice of law in the Hague Principles on Choice of Law in International Contracts. De Jure, v. 44, n. 1, p. 101-110, 2011.

NITSCHKE, Guilherme Carneiro Monteiro. Ativismo Arbitral e Lex Mercatoria. Revista de Arbitragem e Mediação. São Paulo: RT, v. 12, 2015.

POUDRET, Jean-François; BESSON, Sébastian. Comparative law of international arbitration. Ed. Thomson, London: 2007.

RODRÍGUEZ, José Antonio Moreno. Contratación y Arbitraje - contribuciones recientes. Assunción: Centro de Estudios de Derecho, Economía y Política (CEDEP), 2010. 
YNTEMA, Hessel E. "Autonomy" in Choice of Law. The American Journal of Comparative Law, p. 341-358, 1952.

RODAS, Grandino (coord.). Contratos internacionais. São Paulo: Revista dos Tribunais, $3^{\mathrm{a}}$ ed., 2002.

\title{
CONSIDERATIONS ON THE CHOICE OF THE MATERIAL LAW APPLICABLE TO THE MERIT OF DISPUTE IN INTERNATIONAL ARBITRATION AND THE ROLE OF THE ARBITRATOR
}

\begin{abstract}
Arbitration as an alternative method for resolving disputes arising out of contractual relations has assumed increasing importance in the international community. In this paper, we will analyze the problem of the autonomy of the will in international arbitration, arguing if it is possible for the parties to freely choose the material law applicable to the merits of their litigation. In the second part, we will investigate how the arbitrator should act in the absence of an express choice. The methodology used consist in the collection and examination of the national and international doctrinal positions on the subject in question, as well as in the examination of decisions of the Arbitral Tribunals and international diplomas. We will conclude that it is possible, at least in the case of international arbitrations, that the parties choose the substantive right to be applied to the merits of their disputes. In the event of an absence of express choice, the arbitrator must draw from the objective criteria of the contract - the contractual text or context - a solution that points to an implicit choice, since there is no requirement in any modern arbitral statute for the form to be chosen, doesn't preventing the existence of an implicit agreement from being inferred from the conduct of the parties. If it is impossible to ascertain such a choice, either because there is insufficient objective evidence or because the contracting parties disagree on the right to apply, the arbitrator may resort to international diplomas which do not offer a specific method to be followed, granting reasonable discretion to arbitrator.
\end{abstract}

Keywords: Arbitration. International contracts. Autonomy of will. Express choice. Tacit choice. 